\title{
Comparative Efficacy of Melia azedarach Extracts with Amprolium against Experimentally Induced Coccidiosis in Broilers
}

\author{
S. Shekhar ${ }^{*}$, S.K. Shukla ${ }^{2}$, Prakash Bhatt ${ }^{3}$, Mahesh Kumar ${ }^{2}$ and D.S. Bisth ${ }^{4}$ \\ ${ }^{1}$ Krishi Vigyan Kendra (ICAR-NRRI), Jainagar, Koderma, Jharkhand- 825324, India \\ ${ }^{2}$ Department of Veterinary Medicine, ${ }^{3}$ Department of Veterinary Clinics, ${ }^{4}$ Department of \\ Veterinary Surgery, C.V.A.Sc., Pantnagar, G.B.P.U.A.T, \\ Pantnagar-264145, Uttarakhand, India \\ *Corresponding author
}

\section{Keywords \\ Melia azedarach, Amprolium, Coccidiosis}

\section{Article Info}

Accepted:

23 March 2018 Available Online: 10 April 2018

\section{A B S T R A C T}

The present study was planned to investigate the alternative and economical way for treating caecal coccidiosis in Broilers. An experiment was conducted to evaluate the anticoccidial efficacy of aqueous and methanolic extract of Melia azedarach (Bakain) leaves in experimentally induced Eimeria tenella infection in Broilers. Acute toxicity test of herbal extract was conducted in 21 days old broiler. The birds were observed 24 hours for sign of toxicity. At three weeks of age the chicks were randomly divided in to eight groups each group having 15 birds. Group I were healthy control, Group II, III and V were uninfected medicated control group received Amprolium @ $250 \mathrm{mg} / \mathrm{l}$, water, aqueous extract of Melia azedarach leaves @ $1000 \mathrm{mg} / \mathrm{kg}$ body weight, methanolic extract of Melia azedarach leaves @ 1000mg/kg body weight, on day 21 to 28 day of age, once daily respectively, Group IV, Group VI, VII and VIII were infected with 40,000 infected oocysts of Eimeria tenella at 21 days of age. Birds of group IV, VI and VII were treated with Amprolium @ $250 \mathrm{mg} / \mathrm{l}$ water, aqueous extract of Melia azedarach leaves @ 1000mg/kg body weight, and methanolic extract of Melia azedarach leaves @ $1000 \mathrm{mg} / \mathrm{kg}$ body on day 0 to 7 day of post infection respectively. Group VIII kept as infected control and not receive any medicine. No sign of toxicity seen during the acute toxicity test even at highest dose. The birds treated with methanolic extract of Melia azedarach leaves resulted in progressively decrease in severity of clinical sign, faecal score, percent survival, percent weight gain, performance index, average oocyst production, per cent reduction in oocyst production, average oocyst index, average lesion score and percent protection against lesion and restorations of haematological and bio chemicals parameters. The result of this study indicated that methanolic extract of Melia azedarach leaves @1000mg/kg body weight for 7 day having has better anticoccidial activity without affecting the growth of broiler. 


\section{Introduction}

Coccidiosis is one of the most prevalent and economically crucial enteric diseases of poultry. Poultry coccidiosis produced by protozoa belongs to the phylum Apicomplexa, family Eimeriidae and genus Eimeria. Poultry coccidia are generally host specific and each species of Eimeria infects specific part (segment) of the intestine. Eimeria tenella mostly affects young birds of about 5 to 21 days and causes caecal coccidiosis. Commercial broiler farmers are the foremost victims of losses inflicted by coccidiosis, estimating a total economic loss of 95.61 percent (Bera et al., 2010), whereas commercial layer industry shares 3.53 percent of the losses. Coccidiosis is very challenging to control because many species of Eimeria exist at the same time during incidence of the disease in the flock. The birds may contract infection from different species because there is no cross immunity between the different species of Eimeria. Coccidiosis produces detrimental effects on the absorption of nutrients particularly amino acids and glucose and may produce deviation in various biochemical and enzymatic components/ processes and loss of body condition. Coccidial infection also causes structural changes in the intestinal mucosa leading to haemorrhagic enteritis, anaemia, electrolyte imbalance and due to this, the disease is commonly known as Red Dysentery. Conventional methods to control coccidiosis in poultry include use of chemical anticoccidial agents. Poultry farmers use a number of coccidiocidal drugs during outbreak of disease but till date no drug has offered equal protection against all the species of Eimeria. Extensive use of chemicals for the control of poultry coccidiosis leaves some residues in poultry products (meat and eggs) which represent a potential risk to human health and is undesirable for consumer. Recently, there has been a growing interest in plant resources to find out herbs with chemically interesting and biologically significant compound that might serve as lead for potential drug development. Therefore, researchers have felt the need for intensive research into the identification and evaluation of some safer compounds as an alternative to chemical anticoccidials that would satisfy the consumer demand, will be easily available and economical to farmers, and would be close to environmental farming practices. In spite of the fact that many naturally occurring substances have been experimented upon in order to find alternative measures for control of coccidiosis in poultry (Allen and Fetterer, 2002; Dalloul and Lillehoj, 2005), there is still a scanty information regarding locally available herbal products which can provide protection against the effect of coccidial infection.

\section{Materials and Methods}

\section{Collection and identification of plant material}

Leaves of Melia azedarach (Bakain /Maha neem) were locally procured from the vicinity of Pantnagar. The collected specimen were identified and certified by the Medicinal Plants Research and Development Centre (MRDC) of the G.B. P.U.A.T., Pantnagar. Two washings with tap water were given to the fresh leaves after which they were dried in shade for 10 days then leaves were pulverised by mechanical grinder. The powder was sieved through a mesh $(1 \mathrm{~mm})$ and the fine powder thus obtained was stored in clean, wide mouth, air tight, brown colour bottles till further use.

\section{Preparation of plant extracts}

Powder of Melia azedarach were used for preparation of aqueous and methanolic extracts by using cold extraction method. 


\section{Preliminary photochemical analysis}

Qualitative phytochemical analysis of aqueous and methanolic extracts was done by standard method (Arunadeyi, 2003).

\section{Acute oral toxicity of different herbal extract}

Different parameters were studied to assess the acute oral toxicity of herbal extract in commercial broiler chicks.

\section{Experimental coccidian infection}

Pure culture of Eimeria tenella was collected from Division of Parasitology, I.V.R.I., Bareilly, Izatnagar, U. P., India.

For obtaining sufficient stock of oocysts for use in the experiment, four donor broiler of 4 week age, were infected by crop intubation with approximate by $40 \times 10^{3}$ sporulated oocyst collected as above. From $5^{\text {th }}$ to $7^{\text {th }}$ day post infection the total droppings from four infected birds were collected, sporulated, concentrated.

\section{Experimental design}

The experiment was conducted with 120 broiler chicks (day old) purchased from reputed hatchery. After receiving chicks from hatchery, they were arbitrarily divided into eight groups of 15 chicks each. All the chicks were reared under coccidia free condition in horizontal battery brooders and all the possible measures were adopted to keep the flock healthy. The chicks of different groups were reared in individual cage and group will be designated as I to VIII (Table 1).

On day 21 of experiment, broilers of IV, VI, VII and VIII groups were infected by inoculating $1 \mathrm{ml}$ suspension containing 40,000 sporulated oocysts of Eimeria tenella species directly in the pharynx, using a long nozzled 2 $\mathrm{ml}$ plastic pipette. Broilers of healthy and medicated control group (I, II, III, and V) were provided with $1 \mathrm{ml}$ plain distilled water. Before the artificial infection, sub-clinical coccidial infection in broilers were ruled out by standard parasitological methods for 3 consecutive days

\section{Body weight gain/loss}

The body weights of different group of birds were taken individually on $21^{\text {st, }} 28^{\text {th }}$ and $35^{\text {th }}$ days of age. On the basis of these weights, weight gains in different groups of birds were calculated.

\section{Clinical parameters}

Clinical parameters including clinical signs; pre-patent period and mortality rate were recorded.

\section{Parasitological parameters}

Faecal score (FS), Per cent weight gain, Performance index were done as per method described by (Morehouse and Baron, 1970), Oocyst production (Davies et al., 1963), Oocyst index (Hilbrich 1978), Lesion score (Johnson and Reid 1970), Percent protection against lesion (Waletzky, 1970).

\section{Haematological parameters}

Haemoglobin (Hb), Packed cell volume (PCV), Total erythrocyte count (TEC), Total leukocyte count (TLC) and Differential leukocyte count (DLC).

\section{Biochemical parameters}

Alanine Amino Transferase (ALT), Aspartate Amino Transferase (AST), Alkaline Phosphate (ALP), Total Serum Protein (TSP), Serum Albumin (SA), Serum Globulin (SG), 
Albumin Globulin ratio (A:G ratio) and Serum Glucose.

\section{Statistical analysis}

All the observations recorded in this study were subjected to statistical analysis by Snedecor and Cochran (1994).

\section{Results and Discussion}

The aqueous extract residue of Melia azedarach leaves revealed presence of alkaloids, sterols, glycosides, phenols, protein, tannins, flavonoids, terpenoids and its methanolic extract residue contained alkaloids, sterols, glycosides, phenols, protein, tannins, flavonoids, saponins, and terpenoids. The results of present findings are in agreement with previous work of Sumathi et al., (2014).

Preliminary acute toxicity test of methanolic and aqueous extracts Melia azedarach showed that boilers chickens drenched with single oral dose of 1000, 2000 and $5000 \mathrm{mg} / \mathrm{kg}$ b.wt. of methanolic and aqueous extracts did not produce any toxic signs immediately after administration of extracts, birds of all tested sub groups remain alert, showed normal behaviour, normal gait and posture, moved normally in a cage. No mortality was found in any group up to 14 days of observation period. The $\mathrm{LD}_{50}$ of all the extracts residues was more than $5,000 \mathrm{mg} / \mathrm{kg}$ body weight. Dharmalingam et al., (2014) found the aqueous and ethanolic extracts of Melia azedarach leaf @ 2500 $\mathrm{mg} / \mathrm{kg}$ body weight given orally did not produce mortality or any visible toxic signs or general weakness in rats.

Broiler birds infected with coccidiosis showed first clinical signs as off fed, huddling together, drooping of wings, roughness of feathers, dullness and depression, semisolid and watery colour faeces, head press, close eye, pale and droopy plumage and loose faeces. On $7^{\text {th }}$ day post infection extensive bloody droppings with loose faeces were recorded in broiler birds of infected group. Severity of clinical signs varied among different coccidia challenged groups most severe clinical signs were recorded in group VIII. The prepatent period (oocysts were first detected in droppings) of the coccidia/Eimeria infection was $6^{\text {th }}$ day post infection. Mortality in broiler birds of coccidia challenged groups started from $6^{\text {th }}$ day post infection and stopped on $8^{\text {th }}$ day post infection. Broiler birds is treated by methanolic extract, M. azedarach, aqueous extract, $M$. azedarach and amprolium showed mortality $26.67,40.0 \%$ and $13.33 \%$ mortality respectively. Lower mortality per cent noticed in broilers treated with methanolic extract supplemented groups may be due to presence of high antioxidant activity as compared to aqueous extract as shown in our findings and also may be due to the anticoccidial property of these herbs as reported by earlier workers (Anosa and Okoro, 2011). Broilers treated with amprolium and $M$. azedarach had $78.57 \%$ and $50.0 \%$ faecal score respectively. Lee et al., (2007) found that $M$. azedarach extract reveals the anti protozoal activity by inhibiting the cell multiplication as well as the impairment of protein synthesis. Moursi and AL-Khatib (1984), Vidya and Srinivasan (2012) also found that $M$. azedarach leaf extract possesses wound healing and antiulcer activity. Percent weight gain was recorded maximum in broilers of methanolic extract supplemented groups and minimum weight gain percent was recorded in broilers of infected control group (VIII). Higher performance index of broilers was found in amprolium treated group. Performance index of broilers of groups treated with methanolic extract of $M$. azedarach were better than aqueous extract treated group. Singh et al., (2013) found higher performance index in broiler birds supplemented with sprouted Mung in 
comparison to infected control group. Highest average oocyst production per gram of faeces was found in broiler of infected control group $(2,38980)$ and lowest was found in amprolium treated group $(28,234)$. Broilers treated with methanolic extracts of $M$. azedarach showed lower average oocyst production than aqueous extract treated groups. Akthar and Rifaat (1987) found 83\% reductions in OPG count in broiler treated with $M$. azedarach seed powder after 15 days treatment. There was no reduction in percent oocyst production in broilers of infected control group. The treatment groups revealed reduction in oocyst production. Maximum reduction was found in amprolium treated and minimum reduction was in broiler treated with aqueous extract of M. azedarach. Higher average oocyst index were recorded in infected control group
(3.48 \pm 0.22$)$. Among treatment groups lower average oocyst index was observed in broiler of group treated with Amprolium followed by treated with methanolic extract of $M$. azedarach. Average lesion score was maximum in infected control group $\mathrm{XX}$ (3.75) and it was lower in broiler of group VII (1.24 \pm 0.09$)$, which was treated with amprolium. Among herbal treated groups, lower average lesion score was recorded in group VI. Vidya and Srinivasan (2012) also found that methanolic extract of $M$. azedarach leaf possesses wound healing and antiulcer activity. No protection against lesion was seen in infected control group VII. Highest protection $(73.33 \%)$ was recorded in broiler birds treated with amprolium followed by birds treated with methanolic extract of $M$. azedarach leaf (53.33\%).

Table.1 Experimental treatments and their dose of administration

\begin{tabular}{|c|c|c|c|}
\hline Group & $\begin{array}{l}\text { No. of birds } \\
\text { /Group }\end{array}$ & $\begin{array}{c}\text { Oocyst } \\
\text { innoculum } \\
\text { on day } 21\end{array}$ & Details of treatment intervention \\
\hline $\mathbf{I}$ & 15 & & Healthy control \\
\hline II & 15 & & Amprolium @250 mg/lit on 21 to 28 day. \\
\hline III & 15 & & MAAE @ $1 \mathrm{~g} / \mathrm{kg}$ b.wt. on day 21 to 28 day. \\
\hline $\mathbf{I V}$ & 15 & 40,000 & MAAE @ $1 \mathrm{~g} / \mathrm{kg}$ b.wt. on day 0 to 7 DPI. \\
\hline $\mathbf{V}$ & 15 & & MAME @1g/kg b.wt. on day 21 to 28 day. \\
\hline VI & 15 & 40,000 & MAME @ $1 \mathrm{~g} / \mathrm{kg}$ b.wt. on day 0 to 7 DPI. \\
\hline VII & 15 & 40,000 & $\begin{array}{l}\text { Amprolium @ } 250 \mathrm{mg} / \mathrm{l} \text { water on day } 0 \text { to } \\
7 \text { DPI }\end{array}$ \\
\hline$\overline{\text { VIII }}$ & 15 & 40,000 & Infected control \\
\hline
\end{tabular}

In acute phase of disease (5 to $7 \mathrm{DPI}) \mathrm{Hb}$, PCV, TEC, MCH, MCHC, heterophils and monocyte percentage were decreased, whereas MCV, lymphocytes and eosinophils percentage were increased in infected groups than respective uninfected groups. Maximum alterations in haematological parameters were observed in infected control group. Restoration in haematological parameters on day 7 post infection was maximum in amprolium treated group followed by birds treated with methanolic extract of $M$. azedarach leaf. On 14 DPI maximum restorations of haematological parameters was observed in groups treated with methanolic extract of $M$. azedarach leaf. The lower $\mathrm{Hb}$ concentration in acute phase of disease was more or less associated with the severe caecal haemorrhage resulting from the liberation of second generation merozoites, causing massive breakage of the mucosal blood vessels, sloughing of caecal mucosa and 
discharge of large quantity of blood (Nayak and Rai, 1985). It is further aggravated by release of large quantity of histamine from injured tissue resulting in increased blood flow and permeability of the blood vessel. Thereafter, with initiation of gametogenic multiplication the infected birds are on the way of to recovery and they rapidly compensate the blood loss. Consequently there was restoration of haematological parameters (Natt and Herrick, 1955). Adamu et al., (2013) found monocytosis, lymphocytosis, heterophilia and eosinophilia in broiler chickens infected with E. tenella and $E$. brunetti. In coccidia infection, antibody mediated immune response plays a minor role whereas, cell mediated immune response plays a chief role to provide protection against coccidiosis. T lymphocytes appear in Eimeria infection through both cytokine production and a direct cytotoxic attack on infected cells (Lillehoj and Trout, 1993, Yun et al., 2000). Restoration of haemoglobin in all extract groups may be due to the presence of phytochemicals like tannins, glycosides, alkaloids, saponins, flavonoids, polyphenols and reducing sugars in plant extracts which stimulate kidney to the formation or secretion of erythropoietin to stimulate haematopoiesis or could be due to the high iron content of the plant which helps in erythropoiesis (Ohlsson and Aher, 2009).

In acute phase of disease (5 to $7 \mathrm{DPI}$ ) total protein, albumin, globulin and A: $G$ ratio were significantly decreased and glucose level was significantly higher in infected control group. Lesser reduction in total protein, albumin, globulin and A: $\mathrm{G}$ ratio was observed in amprolium treated group Among herbal groups, lesser reduction was noticed in group treated with methanolic extract of $M$. azedarach. The decreased levels of total protein, albumin, globulin and $\mathrm{A}: \mathrm{G}$ ratio in coccidiosis might be attributed to caecal haemorrhage, reduced feed intake and impaired metabolism of proteins (Mondal et al., 2011). Patra et al., (2009) mentioned that marked hypoprotenemia may be contributed by, maldigestion and mal-absorption of nutrient, liver change and severe haemorrhagic enteritis. Suggested that fall in total protein concentration might be due to acute stress that leads to cortisol release and resulting in catabolism of protein. In acute phase of disease, lower elevation in blood glucose level was noticed in birds treated with amprolium and methanolic extract $M$. azedarach. The activities of ALT, AST and ALP were significantly increased in infected control group at 5 and 7 DPI. Lower alteration in the values of ALT, AST and ALP was notice in amprolium treated group. Among other treated groups, lower values were recorded in birds treated $M$. azedarach. On 14 DPI, groups treated with amprolium and methanolic extract of $M$. azedarach revealed almost normal levels of these enzymes. The activities of ALT, AST and ALP were significantly increased in infected control group at 5 and 7 DPI and gradually decreased on 9 DPI onwards. Alteration in ALT activity may be due to less feed intake or due to the hepato cellular damage (Cam et al., 2008). Rao et al., (2012) and Sumathi et al., (2014) reported hepatoprotective action of methanolic extract of Melia azedarach in rats experimentally induced with simvastatin and $\mathrm{CCl}_{4}$. They recorded prominent reduction in AST, ALT, ALP, TP and bilirubin values as compared to the rats of control group.

It was concluded from the study that amprolium was an effective drug against $E$. tenella infection in broiler. Methanolic extract $M$. azedarach leaf were moderately effective against $E$. tenella infection in broilers. Methanolic extract of the herb has tremendous potential to be developed as safe and potential natural alternative to the hazardous and unsustainable chemical anticoccidial drugs. 


\section{References}

Adamu, M., Boonkaewwan, C., Gongruttananun, N. and Vongpakorn, M. 2013. Hematological, biochemical and histopathological changes caused by coccidiosis in chickens, Kasetsart $J$. (Nat. Sci.), 47 : 238-246.

Akhtar, M. S. and Rifaat, S. 1987. Anticoccidial screening of Melia azedarach, L. (Bakain) in naturally infected chickens. Pak. J. of Agri. Sci. 24: 95-99.

Allen, P. C. and Fetterer, R. H. 2002. Recent advances in biology and immunobiology of Eimeria species and in diagnosis and control of infection with these coccidian parasites of poultry. Clinical Micro. Review, 15: 5865.

Anosa, G. N., and Okoro, O. J. 2011. Anticoccidial activity of the methanolic extract of Musa paradisiaca root in chickens. Trop. Anim. Health Prod. 43 (1): $245-8$.

Arunadeyi, R. 2003. Investigation on antiinflammatory, antinociceptive and antipyretic activities of different fraction of Caesaipimia bonducella. Thesis, M.V.Sc. I.V.R.I., Izatnagar, Bareilly. 37 $P$.

Bera, A. K., Bhattacharya, D., Pan, D., Dhara, A., Kumar, S. and Das, A. K. 2010. Evaluation of economic losses due to coccidiosis in poultry industry in India. Agri. Eco. Res. Rev. 23: 91-96.

Cam, Y., Atasever, A., Eraslan, G., Kibar, M., Atalay, O., Beyaz, L., Inci, A. and Liman, B. C. 2008. Eimeria stiedai: experimental infection in rabbits and the effect of treatment with Toltrazuril and Ivermectin. Exp. Parasitol. 119: 164 172.

Dalloul, R. A. and Lillehoj, H. S. 2005. Recents advances in immunomodulation and vaccination strategies against Coccidiosis. Avian Dis. 49: 1-8.

Davies, S. F. M., Joyner, L. P. and Kendall, S.B. 1963. Coccidiosis. $1^{\text {st }}$ edn. Oliver and Boyd Ltd., Edinburg, 221 P.

Dharmalingam, S. R., Rajkumar Madhappan, R., Kumarappan Chidambaram, K., Ramamurthy, S., Gopal, K., Sweth, P. and Senthil Kumar, K. L. 2014. Anti urolithiatic activity of Melia azedarach L. leaf extract in ethylene glycol-induced urolithiasis in male Albino rats. Trop. $J$. of Pharma. Res. 13 (3): 391-397.

Hilbrich, P. 1978. Krankheiten des Geflugels unter besonderer berucksichtigung der Haltung and Futterung. Hermann Kuhn KG, Schwenningenam Necar, Germany.

Johnson, J. and Reid, N. M. 1970. Anticoccidial drugs: lesion scoring techniques in battery and floor pen experiments with chickens. Exp. Para. 28: 30-36.

Lee, Y. S., Chung, I. B., Choi, W. H., Cho, Y. J., Chu, J. P., Min, B. I. and Shin, E. H. 2007. Inhibitory effects of Melia azedarach L. extracts on the growth of Trichomonus vaginalis. Ultrastructural changes of Trichomonu vaginalis by Melia azedarach L. J. Proto zool. Res. 17: $16-24$

Lillehoj, H. S. and Trout, J. M. 1993. Coccidia: A Review of Recent Advances on Immunity and Vaccine Development. Avian Pathol. 22 (1): 331.

Mondal, D. K., Chattopadhyay, S., Batabyal, S., Bera, A. K. and Bhattacharya, D. 2011. Plasma-biochemical indices at various stages of infection with a field isolate of Eimeria tenella in broiler chicken. Vet. World, 4 (9): 404-409.

Morehouse, N.F. and Baron, R.R. 1970. Coccidiosis: Evaluation of coccidiostats by mortality, weight gains and faecal scores. Exp. Para. 28: 25-29.

Moursi, S. and AL-Khatib, I. 1984. Effect of 
Melia azedarach fruits on Gipsing restraint stress induced ulcers in rats. Japan. J. Pharmacol. 36: 527 - 533.

Natt, M. P. and Herrick, C. A. 1955. The effect of Caecal coccidiosis on the blood cells of domestic fowl. Poult. Sci. 34: 1100-1106.

Nayak, D.C. and Rai, P. 1985. Hemogram of chickens experimentally infected with Eimeria spp. Ind. J. Vet. Med. 5: 42-43.

Ohlsson, A. and S. M. Aher, 2009. Early erythropoietin for preventing red blood cell transfusion in preterm and/or low birth weight infants. J. Diet Suppl. 6 (3): 227-251.

Patra, G., Rajkhowa, T.K., Ayub Ali, M., Tiwary, J.G. and Sailo, L. 2009. Studies on clinical, gross, histopathological and biochemical parameters in broiler birds suffered from Eimeria necatrix infection in Aizawl District of Mizoram, India. Int. J of Poult. Sci., 8 (11): 11041106.

Rao, A. S., Ahmed, M. F. and Ibrahim, M. 2012. Hepatoprotective activity of Melia azedarach leaf extract against Simvastatin induced hepatotoxicity in rats. J of Appl. Pharm. Sci. 2 (7): 144148.

Singh, V. S., Palod, J., Vatsya, S., Kumar, R. R. and Shukla S. K. 2013. Effect of sprouted mung (Vigna radiata) supplementation on performance of broilers during mixed Eimeria species infection. Vet. Res. Int. 1 (2):41-45.

Snedecor, G.W. and Cochran, W.G. 1994. Statistical Methods. $8^{\text {th }}$ edn. Iowa University Press, Iowa, U.S.A.

Sumathi, A. 2014. Hepatoprotective activity of methanolic extract of Melia azedarach $L$. on wistar rats. Int. J. Pharm. Bio. Sci. 4 (2): 755 -760.

Vidya, V. and Srinivasan, S. 2012. Wound healing potential of Melia azedarach $\mathrm{L}$. leaves in alloxan induced diabetic rats. Global J. of Res. on Med. Plants \& Indi. Med. 1: 265-271.

Waletzky, E. 1970. Laboratory anticoccidial evaluation trials: Review of design, variables, criteria and predictive value for field use. Exp. para. 28: 42-62.

Yun, C. H., Lillehoj, H. S. and Lillehoj, E. P. 2000. Intestinal immune responses to coccidiosis. Dev. and Comp. Immun. 24: 303-324.

\section{How to cite this article:}

Shekhar, S., S.K. Shukla, Prakash Bhatt, Mahesh Kumar and Bisth, D.S. 2018. Comparative Efficacy of Melia azedarach Extracts with Amprolium against Experimentally Induced Coccidiosis in Broilers. Int.J.Curr.Microbiol.App.Sci. 7(04): 2656-2663. doi: https://doi.org/10.20546/ijcmas.2018.704.303 